\title{
PoHJOISMAINEN PERHEPOLITIIKKA TOIMII MYÖS KOTOUTUMISPOLITIIKKANA ${ }^{1}$
}

\author{
Jussi Tervola: VTT, tutkimuspäällikekö, Terveyden ja byvinvoinnin laitos \\ jussi.tervola@alumni.helsinki.fi \\ Janus vol. 27 (1) 2019, 88-93
}

Perhe on yhteiskuntamme ehkä yksityisin ja eksklusiivisin sosiaalinen yksikkö, ja vanhemman ja lapsen side on usein yksi läheisimmistä ihmissuhteista. Sosiaalipolitiikka toimii taas koko yhteiskunnan tasolla. Julkisessa keskustelussa perhepiirin yksityisyyttä yritetään välillä laajentaa myös sosiaalipolitiikkaa koskevaksi. Esimerkiksi perhepolitiikkaa koskevassa keskustelussa on noussut esille kannanottoja, ettei politiikkojen pitäisi puuttua perheiden sisäisiin asioihin (Timo Soinin Ploki 26.4.2017). Näin perhepolitiikasta yritetään tehdä yksityistä. Ehkä juuri tämä kontrasti äärimmäisen yksityisen ja julkisen välillä on se, mikä tekee perhepolitiikasta tunteita herättävän politiikan alueen.

Huhtikuussa 2018 tarkastetussa väitöskirjassani (Tervola 2018) tutkin pohjoismaisen perhepolitiikan toimivuutta maahanmuuttajien keskuudessa. Jos perhepolitiikka herättää tunteita, maahanmuuttokaan tuskin jättää monia keskustelijoita kylmäksi. Tosin se herättää tunteita toisesta syystä. Kun perhepolitiikassa monilla keskustelijoilla on omakohtaista kokemusta lastenhoidosta, maahanmuuttokeskustelua käyvät usein muut kuin itse maahanmuuttajat. Maahanmuuttajat pysyvät toisena, vieraampana ja ulkopuolisena. Maahanmuuttajataustaisille politiikoille lähetetyissä vihaviesteissä esiintyy kantoja, että maahanmuuttajat olisivat vähemmän oikeutettuja käymään sisäpoliittista keskustelua.

Maahanmuuttoa on ollut niin kauan kuin on ollut kansallisvaltioiden rajoja. Viimeisen puolen vuosisadan aikana liikkuvuutta on ollut moninkertaisesti aikaisempaan verrattuna johtuen ennen kaikkea kasvavasta väestömäärästä ja toisaalta liikenneverkon ja kommunikaatiovälineiden kehityksestä (Castles ym. 2013). Samalla maahanmuutto on myös yhä moninaisempi ilmiö, jonka sisään kätkeytyy hyvin erilaisia kokemuksia ja kohtaloita. Maahanmuuttajia yhdistää ryhmänä ainoastaan se, että he ovat ylittäneet kansallisvaltion rajan pysyväistarkoituksessa.

Muutto on aina toive paremmasta elämästä, mutta parempi elämä tarkoittaa eri ihmisille hyvin erilaista asiaa riippuen lähtökohdista. Jotkut muuttavat oman henkensä uhalla, toiset taas silkasta seikkailun tai menestyksen halusta tai rakkaudesta.Tätä motiivien ja taustojen kirjoa usein painotetaan maahanmuuttotutkimuksessa, mutta silti se jää vähälle huomiolle.

Liikkuvuus on tuonut paljon uusia kysymyksiä kansallisvaltioille ja kansallisille sosiaaliturvajärjestelmille. Ajatus kansasta on verrattain uusi, mutta kuitenkin vanhempi kuin kansalliset sosiaaliturvajärjestelmät. Muuttoliikkeen 
kasvaessa kansojen rajat ovat hämärtyneet ja kysymyksestä, kenelle pitäisi suoda pääsy maahan ja sen tarjoamiin etuuksiin, on tullut keskeinen kiistanaihe (Sainsbury 2006). Ne, joille suodaan pääsy maahan ja oikeus sen sosiaaliturvajärjestelmään, ovat velvoitettuja "kotoutumaan" eli tulemaan jollain tasolla samanlaiseksi kuin kohdemaan väestö. Vaikka kotoutumiskäsitettä käytetään hyvin ylimalkaisesti, yleensä sillä viitataan ennen kaikkea työllisyystilanteen parantumiseen (Ager \& Strang 2008).

Suomalaisen sosiaalipolitiikan keskeisin tavoite on ollut toimeentulon turvaaminen inhimillisten riskien, kuten työttömyyden, sairauden, perheellistymisen tai vanhuuden varalle. Kotoutumistavoite on luonut myös oman politiikanhaaransa, kotouttamispolitiikan. Pohjoismaisessa kontekstissa se käsittää erinäisiä työllistämistä edistäviä toimenpiteitä, kuten kielikursseja, mutta toisaalta myös kulttuuritietouden lisäämistä. Kotoutumista ei voida kuitenkaan irrottaa muista sosiaalipolitiikan lohkoista. Se pikemminkin läpäisee ne kaikki. Se on voimakkaasti läsnä asumispolitiikassa eikä vähiten perhepolitiikassa, joka on väitöskirjani keskiössä.

\section{Perhepolitimkan moninaiset TAVOITTEET JA NIIDEN TOTEUTUMINEN}

Perhepolitiikka on siitä erityinen politiikanlohko, että sille on vuosien saatossa annettu hyvin suuri määrä tavoitteita. Perheiden toimeentulon turvaamisen lisäksi sen on toivottu kannustavan lasten hankkimiseen, edistävän naisten työssäkäyntiä ja toisaalta miesten osallistumista lastenhoitoon. Sen on haluttu edistävän työn ja perheen joustavaa yhteensovittamista, poistavan lasten kokemaa köyhyyttä ja toisaalta tukevan lasten kehitystä korkealaatuisilla palveluilla (Saraceno ym. 2012). Lisäksi erityisesti Suomessa perhepolitiikalla on haluttu edesauttaa perheiden valinnanvapautta lastenhoidon eri vaihtoehtojen suhteen (Hiilamo \& Kangas 2009).

Edellä luetellut tavoitteet voivat olla ristiriidassa monella tavalla, ja siksi niiden yhteensovittaminen on haastavaa. Tämä näkyi myös perhevapaauudistuksen valmistelussa vuoden 2018 alussa. Kun uudistus rajoitettiin budjettiraameihin, moni ei yllättynyt, että uudistus lopulta kariutui.Yksi keskeinen uudistuksen tavoite oli perhevapaiden tasaisempi jakautuminen vanhempien kesken. Kun miesten palkat ovat keskimäärin korkeammat kuin naisten, on selvää, että isien vapaiden pidentäminen lisää julkisia kustannuksia. Yhtä lailla tiedetään, että korkealaatuinen varhaiskasvatus on kallista lyhyellä aikavälillä, mutta sen pitkän aikavälin hyötyjä on vaikeampi arvioida. Suomessa Tuomas Kosonen ja Kristiina Huttunen (2018) eivät löytäneet pitkän aikavälin vaikutuksia kouluarvosanoihin tai kouluttautumiseen. Yhdysvalloissa kohdennetulla varhaiskasvatuksella on havaittu kuitenkin merkittäviä pitkän aikavälin vaikutuksia (Heckman ym. 2010).

Sosiaalipolitiikan tavoitteiden toteutumisen arviointi jää usein vajaaksi, etenkin jos ilmiöstä ei ole kerätty tai pystytty keräämään tietoa. Luotettavinta arviointia pystytään tekemään satunnaiskokeilla ja muilla valikoitumisesta vapailla asetelmilla. Koska sosiaalipolitiikan perimmäisiä kohteita ovat ihmiset, joiden käyttäytymistä määrittävät hyvin monimutkaiset mekanismit, 
sosiaalipolitiikalla on usein tarkoittamattomia seurauksia. Viimeaikaisten tutkimusten mukaan kotihoidon tuki näyttää esimerkiksi kasvattavan synnytysvälejä ja lykkäävän eroamista (Andersen ym. 2018; Morosow ym. 2018), mikä ei ole ollut sen tavoite.

Sosiaalipolitiikan vaikutukset voivat olla hyvin erilaisia eri väestöryhmissä. Tiedetään esimerkiksi, että isille suunnatut perhevapaat ovat tasanneet sukupuolten eroja lastenhoidossa etenkin hyvin koulutettujen vanhempien perheissä (esim. Saarikallio-Torp \& Haataja 2016).Vastaavasti varhaiskasvatuksella on todettu olevan suotuisia vaikutuksia lapsiin etenkin alemmissa sosioekonomisissa ryhmissä (Melhuish ym. 2015). Myös sukupuoli, ikä, syntyperä ja etnisyys ovat sosiaalisia kategorioita, joiden mukaan politiikan vaikutusten on todettu vaihtelevan.

\section{MaAhanmuUttajaväESTÖN ERITYISPIIRTEET PERHEPOLITIIKAN KOHTEENA}

Keskeinen perhepolitiikan tavoite etenkin pohjoismaisessa kontekstissa on ollut edesauttaa sukupuolten tasa-arvoa työelämässä ja lastenhoidossa. Tätä on edistetty perhevapaakorvauksilla kummallekin vanhemmalle sekä tarjoamalla matalakustanteisia päivähoitopalveluja. Nämä toimenpiteet ovat edesauttaneet kiistattomasti sitä, että Pohjoismaissa on maailman pienimmät sukupuolierot taloudellisessa itsenäisyydessä ja kouluttautumisessa (World Economic Forum 2015). Kuitenkin tiedetään, että maahanmuuttajien keskuudessa sukupuolierot esimerkiksi perhevapaiden käytössä ja työvoimaan osallistumisessa ovat suurempia (Antecol 2000; Duvander 2010). Usein nämä erot heijastavat eroja maahanmuuttajien lähtömaissa (Antecol 2000; Frank \& Hou 2015).

Perhepolitiikalla on keskeinen merkitys vanhempien lisäksi myös lapsille. Subjektiivinen päivähoito-oikeus on taannut esimerkiksi Suomessa suhteellisen tasa-arvoisen pääsyn ja korkean käyttöasteen varhaiskasvatuksessa. Tämä julkinen interventio on perusteltu: tutkimuskirjallisuus on osoittanut, että osallistuminen korkealaatuiseen varhaiskasvatukseen tietyssä iässä edesauttaa lapsen sosialisaatiota ja integraatiota yhteiskuntaan, etenkin matalammissa sosioekonomisissa ryhmissä ja maahanmuuttajien keskuudessa. Toisaalta tiedetään, että nämä ryhmät, jotka hyötyisivät varhaiskasvatuksesta eniten, ovat siinä aliedustettuina (Leseman 2002).

Perhepolitiikan toiminnan kannalta maahanmuuttajat muodostavat erityisryhmän, sillä heillä voi olla erilaisia sosiaalisia normeja ja kulttuurisia käsityksïä, jotka määrittävät lastenhoitovalintoja (esim. Liang ym. 2000). Normit voivat koskea kysymyksiä, minkä ikäisenä lapsi tarvitsee varsinaista varhaiskasvatusta ja kumman vanhemman tulisi hoitaa lasta (Leseman 2002; Frank $\&$ Hou 2015). Maahanmuuttajien asema vähemmistönä, esimerkiksi kielen ja kulttuurin suhteen, voi määrittää heidän valintojaan. Valinnoissaan he voivat vaalia oman kieli- ja kulttuuriperintönsä siirtymistä lapselle (Miller ym. 2014; Lastikka \& Lipponen 2016). Tai päinvastoin, he haluavat taata hoitovalinnoillaan, että lapsi omaksuu valtaväestön kielen ja kulttuurin (Obeng 2007; Uttal 2011). Lisäksi heikommasta kielitaidosta johtuen tiedon saatavuus 
eri vaihtoehdoista voi olla heikompaa (Duvander 2010). Myös vanhempien heikompi työmarkkina-asema ja jopa syrjintä työmarkkinoilla voi määrittää valintaa esimerkiksi isän vapaiden käytön suhteen. Kaikki nämä lukuisat syyt tekevät maahanmuuttajista erityislaatuisen ihmisryhmän lastenhoitovalintojen suhteen.

\section{MAAHANMUUTTAJAPERHEIDEN POIKKEAVAT LASTENHOITOVALINNAT EIVÄT SELITY VAIN ERILAISELLA TALOUDELLISELLA ASEMALLA}

Väitöskirjassani tutkin maahanmuuttajaperheiden lastenhoitovalintoja rekisteriaineiston avulla Suomessa ja Ruotsissa. Aineisto on koottu yhdistämällä perhe-etuuksien maksutietoja väestö- ja verorekisterien tietoihin vuosilta 1999-2010. Neljä artikkelia piirtävät moniulotteisen kuvan politiikan ja talouden sekä toisaalta normien ja preferenssien merkityksestä maahanmuuttajien lastenhoitovalinnoissa. Kaksi ensimmäistä artikkelia perustuu Suomi-Ruotsi-vertailuun, ja ne on tehty yhteistyössä Tukholman yliopiston tutkijoiden kanssa.

Väitöskirjani ensimmäinen artikkeli (Tervola ym. 2017) osoittaa, että perhevapaan kiintiöinti isälle tasaa sukupuolieroja vapaiden käytössä Ruotsissa kantaväestön lisäksi myös maahanmuuttajaväestössä. Suomessa perhevapaat eivät ole tavoittaneet maahanmuuttajaisiä vielä 2000-luvun ensimmäisellä vuosikymmenellä. Eroja maiden välillä voi selittää se, että toisin kuin Ruotsista, Suomesta puuttui tutkimuksen aikaan vielä varsinainen isäkiintiö, joka olisi riippumaton äidin vapaiden käytöstä.
Suomessa riippumaton ja itsenäinen isäkiintiö tuli voimaan vuonna 2013.

Toisessa väitöskirja-artikkelissani (Mussino ym. 2017) selvitämme sukupuolinormien vaikutusta isien vapaiden käyttöön maahanmuuton ja sosialisaatioteorian avulla. Tulokset tukevat näkemystä, että lapsuudessa ja nuoruudessa opitut sukupuolinormit vaikuttavat isien perhevapaiden käyttöön vielä aikuisenakin.

Kahdessa viimeisessä artikkelissa (Tervola 2015; Tervola 2016) tutkin maahanmuuttajaperheiden kotihoidon tuen käyttöä eri tilanteissa. Tulosten perusteella maahanmuuttajaperheet Suomessa käyttävät kotihoidon tukea pidempään kuin kantaväestö, mikä selittyy vain osittain havaituilla sosioekonomisilla eroilla. Sen sijaan yli kolmevuotiaat sisarukset viedään maahanmuuttajaperheissä varhaiskasvatukseen selvästi useammin kuin kantaväestössä, mikä ei selity eroilla asuinpaikoissa tai taloudellisissa tekijöissä. Uskottavin selitys on, että maahanmuuttajaperheissä tunnistetaan varhaiskasvatuksen hyödyt esimerkiksi kielenoppimiselle. Toisaalta kuntien viranomaiset saattavat osaltaan ohjata maahanmuuttajaperheiden valintoja, mutta yleisiä ohjeita maahanmuuttajien ohjaamiseen ainakaan suurimmilla kunnilla ei ole. Loppujen lopuksi se on perheiden oma valinta.

Tulosten perusteella voidaan sanoa, että pohjoismainen perhepolitiikka isille suunnattuine vapaineen ja julkisine varhaiskasvatuspalveluineen toimii osaltaan myös kotoutumispolitiikkana. Ruotsin esimerkki näyttää, että perhevapaat voivat olla toimiva työkalu sukupuolen tasa-arvon edistämisessä 
maahanmuuttajaväestössä. Lisäksi subjektiivinen oikeus varhaiskasvatukseen myös silloin, kun vanhempi on syystä tai toisesta kotona, edesauttaa etenkin maahanmuuttajataustaisten lasten kielenoppimista ja myöhempää integraatiota yhteiskuntaan.

\section{VIITE}

1 Puheenvuoro perustuu Helsingin yliopistossa 13.4.2018 tarkastetun yhteiskuntapolitiikan väitöskirjan lectio praecursoriaan.Väitöskirja on tehty työsuhteessa Kelan tutkimusryhmään. Tutkimusta on rahoittanut Kelan lisäksi Suomen akatemian Tackling Inequalities in Time of Austerity -hanke (nr. 293103).

\section{KirJallisuUs}

Ager, Alastair \& Strang, Alison (2008) Understanding integration: A conceptual framework. Journal of refugee studies 21 (2), 166-191. https://doi.org/10.1093/ jrs/fen016

Andersen, Synøve N. \& Drange, Nina \& Lappegård, Trude (2018) Can a cash transfer to families change fertility behaviour? Demographic Research 38, 897-928. https://doi.org/10.4054/ DemRes.2018.38.33

Antecol, Heather (2000) An examination of cross-country differences in the gender gap in labor force participation rates. Labour Economics 7 (4), 409426. https://doi.org/10.1016/S09275371(00)00007-5

Castles, Stephen \& De Haas, Hein \& Miller, Mark (2013) The age of migration: International population movements in the modern world. Basingstoke: Palgrave Macmillan.

Duvander, Ann-Zofie (2010) Immigrants' use of parental leave in Sweden. Teoksessa Lisbeth Knudsen \& Linhardt Olsen (toim.) Our Demographic $\mathrm{Fu}-$ ture-a Challenge. On the Need for Demographic Analyses. Aalborg: Scandina- vian Population Studies 14, 203-224.

Frank, Kristyn \& Hou, Feng (2015) Sourcecountry Gender Roles and the Division of Labor Within Immigrant Families. Journal of Marriage and Family 77 (2), 557-574. https://doi.org/10.1111/ jomf.12171

Heckman, James J. \& Moon, Seong Hyeok \& Pinto, Rodrigo \& Savelyev, Peter A. \& Yavitz, Adam (2010) The rate of return to the HighScope Perry Preschool Program. Journal of Public Economics 94 (1), 114-128. https://doi.org/10.1016/j. jpubeco.2009.11.001

Hiilamo, Heikki \& Kangas, Olli (2009) Trap for women or freedom to choose? The struggle over cash for child care schemes in Finland and Sweden. Journal of social policy 38 (3), 457-475. https:// doi.org/10.1017/S0047279409003067

Kosonen, Tuomas \& Huttunen, Kristiina (2018) Kotihoidon tuen vaikutus lapsiin. Tutkimuksia 115. Helsinki: Palkansaajien tutkimuslaitos.

Lastikka, Anna-Leena \& Lipponen, Lasse (2016) Immigrant Parents' Perspectives on Early Childhood Education and Care Practices in the Finnish Multicultural Context. International Journal of Multicultural Education 18 (3), 75-94. https:// doi.org/10.18251/ijme.v18i3.1221

Leseman, Paul (2002) Early childhood education and care for children from low-income or minority backgrounds. A Paper for Discussion at the OECD Oslo Workshop.

Liang, Xiaoyan \& Fuller, Bruce \& Singer, Judith D. (2000) Ethnic differences in child care selection: The influence of family structure, parental practices, and home language. Early Childhood Research Quarterly 15 (3), 357-384. https://doi. org/10.1016/S0885-2006(00)00071-5

Melhuish, E. \& Ereky-Stevens, K. \& Petrogiannis, K. \& Ariescu, A. \& Penderi, E. \& Rentzou, K. \& Tawell, A. \& Slot, P. \& Broekhuizen, M. \& Leseman, P. (2015) A review of research on the effects of early childhood education and care (ECEC) upon child development. CARE project. Curriculum Quality Analysis and Impact Review of European Early Childhood Education and Care (ECEC). http:// ecec-care.org/resources/publications/ 
Miller, Portia \& Votruba-Drzal, Elizabeth \& Coley, Rebekah Levine \& Koury, Amanda S. (2014) Immigrant families' use of early childcare: Predictors of care type. Early Childhood Research Quarterly 29 (4), 484-498. https://doi.org/10.1016/j. ecresq.2014.05.011

Morosow, Kathrin \& Jalovaara, Marika \& Härkönen, Juho (2018) Cash-for-Care use and Union Dissolution in Finland. Stockholm Research Reports in Demography 18. Stockholm: Stockholm University.

Mussino, Eleonora \& Tervola, Jussi \& Duvander, Ann-Zofie (2017) Decomposing the Determinants of Fathers' Parental Leave Use: Evidence from migration between Finland and Sweden. Stockholm Research Reports in Demography 17. Stockholm: Stockholm University.

Obeng, Cecilia Sem (2007) Immigrants Families and Childcare Preferences: Do Immigrants' Cultures Influence Their Childcare Decisions? Early Childhood Education Journal 34 (4), 259-264. https://doi.org/10.1007/s10643-0060132-9

Saarikallio-Torp, Miia \& Haataja, Anita (2016) Isien vanhempainvapaiden käyttö on yleistynyt. Ketkä isistä vapaita käyttävät ja ketkä eivät? Teoksessa: Anita Haataja, Ilpo Airio, Miia Saarikallio-Torp \& Maria Valaste (toim.) Laulu 573566 perheestä. Helsinki: Kela, 80-115.

Sainsbury, Diane (2006) Immigrants' social rights in comparative perspective: welfare regimes, forms in immigration and immigration policy regimes. Journal of European Social Policy 16 (3), 229-244. https://doi. org/10.1177/0958928706065594
Saraceno, Chiara \& Leira, Arnlaug \& Lewis, Jane (2012) Introduction: Families and states. Teoksessa: Chiara Saraceno \& Jane Lewis \& Arnlaug Leira (toim.) Families and family policies, Volume I. Cheltenham: Edward Elgar, xxxix.

Tervola, Jussi (2015) Maahanmuuttajien kotihoidon tuen käyttö 2000-luvulla. Yhteiskuntapolitiikka 80 (2), 121-133. https://doi.org/10.1093/sp/jxx006

Tervola, Jussi (2016) Vanhempi kotona, lapsi päivähoidossa? Tarkastelu lastenhoitovalinnoista maahanmuuttajaperheissä. Teoksessa: Anita Haataja, Ilpo Airio, Miia Saarikallio-Torp \& Maria Valaste (toim.) Laulu 573566 perheestä. Lapsiperheet ja perhepolitiikka 2000-luvulla. Helsinki: Kela, 160-180.

Tervola, Jussi (2018) Supporting gender equality and integration. Immigrant families' child care choices in the Nordic policy context. Sosiaali- ja terveysturvan tutkimuksia 149. Helsinki: Kela.

Tervola, Jussi \& Duvander, Ann-Zofie \& Mussino, Eleonora (2017) Promoting Parental Leave for Immigrant FathersWhat Role Does Policy Play? Social Politics: International Studies in Gender, State \& Society 24 (3), 269-297.

Uttal, Lynet (2011) Taiwanese immigrant mothers' childcare preferences: socialization for bicultural competency. Cultural Diversity and Ethnic Minority Psychology 17 (4), 437. https://doi.org/10.1037/ a 0025435

World Economic Forum (2015) The Global Gender Gap Report 2015. Cologny: World Economy Forum. 